\title{
College STAR for Librarians
}

$\mathrm{P}$ ersons with learning disabilities face particular challenges when using academic libraries. As libraries seek to improve this situation, knowledge of current programs and relevant theories outside of library science can inform our choices. For librarians in the University of North Carolina system, a program of particular interest is called College STAR.

College STAR (Supporting Transition, Access, and Retention: A UNC System Project Supporting Students with Learning Differences) is a program intended to improve higher education success rates for students with formally-identified learning disabilities through direct interventions, faculty innovation, and research. Initiated by its principle investigator, Dr. Sarah Williams of ECU, the project is dedicated to the development and implementation of educational models that better meet the needs of students who encounter unnecessary barriers in traditional higher education methods. College STAR includes opportunities for participation and learning for librarians, presenting a potential opportunity to meaningfully improve library services for a population whose needs may have been neglected or poorly understood.

College STAR is funded by grants from the OAK Foundation and the North Carolina GlaxoSmithKline Foundation with the aim of making University of North Carolina (UNC) campuses more welcoming to students with diagnosed learning disabilities, Attention Deficit Hyperactivity Disorder (ADHD), or learning differences that may not fit an established diagnostic model, all of whom may benefit from an environment with more inclusive teaching strategies. The program consists of two components. Component A concerns the development of support programs such training in time management skills and study habits for students with learning differences whose needs have not been adequately addressed in the past. This component includes the identification and recruitment of students who will communities whose shared research aims to explore technologies and techniques of UDL for use in teaching. On the UNCG campus, ACCESS (Accessing Campus Connections and Empowering Student Success) is a three year research project designed to help students with ADHD develop the skills needed to succeed in the college environment. At ASU, AS-U-R is a support

\section{C College STAR is funded by grants from the OAK} Foundation and the North Carolina GlaxoSmithKline Foundation with the aim of making University of North Carolina (UNC) campuses more welcoming to students with diagnosed learning disabilities 9

be provided appropriate support during their undergraduate years. Component $B$ focuses on the development of improved instructional strategies and encourages faculty support to expand the understanding and implementation of Universal Design for Learning (UDL). Three UNC campuses, East Carolina University (ECU), the University of North Carolina at Greensboro (UNCG), and Appalachian State University (ASU) currently have active College STAR programs and expansion to other campuses is planned.

Participating campuses design their own local programs. At ECU, the program consists of Project STEPP (Supporting Transition and Education through Planning and Partnerships) which provides academic and life-skills support for a group of students with learning disabilities, and Pirate CREWS (Collaborating for Retention and Engagement With ongoing Support), a number of faculty learning program for students with Executive Function Challenges (EFC) that includes cognitive skills training and supervised study. ASU also has faculty learning communities and on-going training opportunities for course redesign and UDL. There are plans to expand the College STAR program to other UNC campuses and the program aims to benefit the community college system and K-12 education as well.

College STAR's educational philosophy is founded on Universal Design for Learning. UDL advocates offering learners multiple means of representation, of action and expression, and of engagement. (Please see cast.org for a complete explanation) Simply put, UDL advocates offering students options in the way information is communicated, in the way knowledge and learning are demonstrated, and in the way they are engaged in the learning process. Libraries can focus attention on representation and 
engagement. For representation, keep in mind that there are many learning styles and preferences. If we can offer the same information in multiple ways, i.e. print, video, audio, more users will have access. Engaging patrons should also give them options. Some may prefer email, chat, or phone to inperson reference, for example. The benefits reach beyond patrons with learning disabilities, of course. It is easy to imagine a person with a speech or hearing impairment welcoming the option of chat or email, for example. Likewise, those with mobility issues will surely appreciate the ability to communicate remotely, rather than coming to the library.

Underlying the UDL philosophy is that for some students, failure is caused by pedagogical design rather than lack of effort or ability. An analogy of a physical disability is a useful way to explain it. Consider the case of a person who relies on a wheelchair for mobility. If he finds himself unable to enter a building because of a step and a manual swinging door, the fault of this inability (or disability) lies with the design of the door, not with his method of ambulation. The door and step were designed with persons of certain abilities in mind, those who can walk and have the strength to open the door. But, if the goal is to provide entry to the building rather than to test peoples' ability to mount steps and open swinging doors, the design has failed to meet everyone's needs because the person in the wheelchair is unable to achieve the goal. However, it is possible from the beginning of the design to consider the needs of a wider range of people than those who can walk. Designing with a wheelchair user in mind will benefit others as well. People who can walk are not slowed or inconvenienced by entering a building through an automatic door with a flat entrance surface. They are likely to find the design superior to the step and swinging door. Parents pushing strollers and people with full hands will find the improved design as welcome as a wheelchair user.

In libraries, the goal is to maximize access to information for all patrons. Considering the needs of as many people as possible in the initial design of services, instruction, tutorials, research guides, etc. will support this goal. For example, since we know that some patrons will have difficulty processing written instructions, it is a simple modification to offer video instructions as well. As technology advances and our understanding of the needs of diverse learners expands, our ability to offer alternatives grows. We should be focused on design that meets the needs of all. Libraries have largely responded to the needs of patrons with mobility challenges, and their needs are now considered in building design. The needs of those with learning disabilities can likewise be accommodated.

The example of the College STAR is inspiring in itself. There are, however, more tangible benefits of the program for libraries. Librarians on campuses with College STAR programs (ECU, UNCG, and ASU), may participate in College STAR's Shared Learning Conference. The conference includes presentations and poster sessions about UDL applications being developed in the UNC system. The College STAR website makes information of this type available to all through learning modules hosted on its website. The website includes modules that are applicable to the practice of academic librarianship such as "Promoting Student Engagement" and "Using Clickers." Librarians on participating campuses may join or start supported learning communities to research UDL issues. All librarians have access to learning modules linked from College STAR's website and on the companion cast.org which includes some more general modules such as "Post-secondary Education and Universal Design for Learning."

As academic libraries work to improve access for people with learning disabilities, examples such as College STAR can offer guidance and inspiration. The theories and practices of UDL can help us widen our design practices to include patrons differing abilities and talents.

\section{References}

1 The terms 'learning differences' and 'learning disabilities' are both in current usage. They are used interchangeably in this essay

2 Information about College STAR in this essay is taken from http://www.collegestar.org/

${ }^{3}$ Information about Universal Design for Learning in this essay is taken from http://www.cast.org/index.html 